\title{
A Model for Energy Pricing with Stochastic Emission Costs
}

\author{
Robert J. Elliott ${ }^{\mathrm{a}, 2}$, Matthew R. Lyle ${ }^{* a, 1}$, Hong Miao ${ }^{\mathrm{b}, 3}$ \\ ${ }^{a}$ Haskayne School of Business, Scurfield Hall, University of Calgary, 2500 University Dr. NW \\ Calgary, Alberta, Canada, T2N 1 N4 \\ ${ }^{b}$ Department of Finance and Real Estate, College of Business, Colorado State University, 1272 \\ Campus Delivery, Fort Collins, CO 80523, USA
}

\begin{abstract}
We use a supply-demand approach to value energy products exposed to emission cost uncertainty. We find closed form solutions for a number of popularly traded energy derivatives such as: forwards, European call options written on spot prices and European Call options written on forward contracts. Our modeling approach is to first construct noisy supply and demand processes and then equate them to find an equilibrium price. This approach is very general while still allowing for sensitivity analysis within a valuation setting. Our assumption is that, in the presence of emission costs, traditional supply growth will slow causing output prices of energy products to become more costly over time. However, emission costs do not immediately cause output price appreciation, but instead expose individual projects, particularly those with high emission outputs, to much more extreme risks through the cost side of their profit stream. Our results have implications for hedging and pricing for producers operating in areas facing a stochastic emission
\end{abstract}

\footnotetext{
${ }^{*}$ Corresponding Author

${ }^{1}$ mrlyle@ucalgary.ca

${ }^{2}$ relliott@ucalgary.ca

${ }^{3}$ Hong.Miao@business.colostate.edu
} 
cost environment.

Key words: Energy Pricing, Energy Derivatives, Emissions Uncertainty, Project Valuation

\section{Introduction}

Across the globe the negative impact of emissions on the environment has become a central issue in economic and political debate. As a result, governments are beginning to formulate policies and measures to reduce the impact of human economic activity on the environment. By design, these new policies will have implications on energy intensive industries such as electricity generation, oil extraction (including oil sands production), and the production of metals such as copper and gold. These industries are fundamental components of the global economy. In particular, electricity generation, which is essential for industrial countries, and oil production, which is linked to a multitude of consumption goods, play central roles in both the current and future economic welfare of the planet. However, the energy industry is filled with risk and uncertainty. The prices of energy products are highly volatile and notoriously difficult to model, as noted by numerous researchers and practitioners, (see for example (Eyderland and Wolyniec, 2003) and the references within). These modeling challenges include mean reversion, price spikes and jumps, extreme volatility, and complex cyclical behavior. Such characteristics make forecasting price paths and the pricing of financial contracts difficult. This, however, is necessary when planning large scale investments, such as the building or purchasing of power generators and evaluating the risks associated with an oil sands project. In addition to these complexities, the introduction of a cost for emissions system to mitigate Greenhouse Gas (GHG) emissions has 
made operating in the energy market even more difficult.

With the general increase in awareness of the importance of emissions reduction, we expect that policies will soon be in place that will force energy intensive projects to be evaluated differently. This will require the re-adjustment of pricing methods and models in the near future and is an area of research that will require attention. Proper pricing models that incorporate the risks and rewards associated with energy investments are an absolute necessity when determining whether to invest in a project or not. The objective of this paper is to provide appropriate models.

In January 2005 the European Emissions Trading Scheme, (EU ETS), was launched. This is considered a new element in energy industry operations. Basically the EU ETS restricts the overall amount of $\mathrm{CO}_{2}$ emissions in EU countries by allocating a limited number of so called EU emission allowances. Those allowances can be traded between the participants. Since then, research has been done to investigate the price dynamics of emission allowances and the impacts of emissions trading on energy markets.

Some of the empirical research which attempts to describe the behaviour of emission prices includes: Benz and Trück (2009), who analyze the short-term spot price behavior of the $\mathrm{CO}_{2}$ emission allowance of the EU ETS system and suggest the use of Markov switching, and AR-GARCH models for modeling its spot price. Seifert and Ührig-Homburg (2008), present a tractable stochastic equilibrium model reflecting stylized features of the EU ETS and analyze the resulting $\mathrm{CO}_{2}$ spot price dynamics. Paolella and Taschini (2008), analyze two emission permits markets, $\mathrm{CO}_{2}$ in Europe, and $\mathrm{SO}_{2}$ in the US, and suggest a model for dealing with the unique stylized facts of this type of data. They demonstrate that 
their model is more effective in terms of model fit and out-of-sample value-atrisk forecasting compared to models commonly used in risk management contexts. Daskalakis and Markellos (2009), show that the prohibition of banking of emission allowances between distinct phases of the EU ETS has significant implications for futures pricing and develop a framework for the pricing and hedging of intra-phase and inter-phase futures and options on futures. Frauendorfer and Güssow (2009), introduce a modeling framework that considers the influence of emission trading on portfolio problems in the electric power sector by applying clean valuation schemes that particularly take fuel costs and emission efficiency in combination with investment possibilities, and generation flexibility into account.

The EU ETS seems to have produced an environment where large profits are obtained by electricity producers. Kara et al. (2008), assess the impacts of the EU emission trading system on the Nordic electricity market and on the position of various market participants. They find that emissions trading brings large windfall profits to the electricity producers. Daskalakis and Markellos (2009) analyze the data from three major EU ETS major markets, the EES, Nord Pool and Powernext, and find that the allocation of free allowances and their unrestricted trading enable electricity producers to accomplish windfall profits in the derivatives market at the expense of other market participants. Their results are consistent with Kara et al. (2008). Veith et al. (2009), measure the EU ETS's economic consequences and show that returns on common stock of the largest affected industry, power generation, are positively correlated with rising prices for emission rights. Their results imply that the market predicts that firms are not only able to pass on their share of regulatory burden to customers but even achieve windfall profits by overcompen- 
sating for the costs. Bunn and Fezzi (2007), show how the prices of carbon and gas jointly influence the equilibrium price of electricity and derive the dynamic pass-through of carbon into electricity price and the response of electricity and carbon prices to shocks in gas price.

Previous studies show that the electricity industry actually passes the emission costs to customers. It is reasonable to expect the emission costs will significantly affect both the spot prices of energy products and derivatives on energy commodities. Therefore, appropriate models for energy spot prices and energy commodity derivatives should include the impact of emission costs. In this paper, we shall address the emission cost effects on energy pricing and develop appropriate models for pricing both energy spot and derivatives. Where our modeling approach differs from some of the previous studies is that we allow output prices to react to emission. Our goal is to formulate a model which is applicable to the general energy industry, which includes Oil and other global energy commodities. Though electricity producers may be able to instantaneously pass along the costs of emissions, we believe that many other energy producers will not, our model is designed to address the case where costs gradually become incorporated into energy prices. Additionally, we believe that the widely recognized behaviour of producers within the EU ETS and the wind fall profits which they received will cause policy makers to design a market such that emission costs are more gradually incorporated into the output price of the good. To the best of our knowledge, this paper is the first to consider a bottom-up energy pricing model which incorporates emission costs and uncertainty. We use a 'hybrid' model framework which combines the fundamentals of energy commodities and stochastic dynamics.

A number of hybrid models have been proposed in the literature. For example, 
Anderson and Davison (2008), develop a hybrid system econometric model for electricity spot prices and test the model using both the Pennsylvania-New JerseyMaryland (PJM) and Alberta market data. For more details of the model, see also Anderson (2004), and Davison et al. (2002). Research has been undertaken in energy, particularly electricity, and derivatives pricing; see, for instance, Longstaff and Wang (2004), Bessembinder and Lemmon (2002), Deng and Oren (2006), Lucia and Schwartz (2002), Vucetic et al. (2001), and most recently Pirrong and Jermakyan (2008), Cartea and Villaplana (2008), and Lyle and Elliott (2009). In all these studies, none consider the impact of emissions or their stochastic nature. Our contribution is to provide a realistic model which is still simple enough to maintain mathematical tractability while incorporating emission costs into energy pricing.

The paper will be presented as follows: in section 2 we derive an equilibrium price for an asset given assumed supply and demand functions. There are a large number of energy derivative products which are used for hedging, operating, and speculation on a daily basis within the energy sector, and section 3 provides solutions for the price of a forward contract, a European call option written on the spot price and the price of a European call option written on a forward contract. Section 4 provides insight into how the model can be calibrated. In section 5 we propose a project valuation model and include simulation results to indicate how emissions affect the value of energy producing assets. In section 6 we conclude the paper and indicate several areas of future research. 


\section{The Model}

We begin with the assumption that there is both a supply and demand function for a commodity. Each of these functions has a time component, say $f_{i}(t)$, which is assumed to be stochastic, and a price component, say $g_{i}(P)$. Here $P$ is price and $i \in\{s, d\}$, indicates supply and demand, respectively. Thus, for supply we write:

$$
S=S(t, P)=f_{s}(t) g_{s}(P)
$$

and for demand

$$
D=D(t, P)=f_{d}(t) g_{d}(P)
$$

We impose the following requirements on supply and demand functions:

$$
\frac{\partial S}{\partial f_{s}}>0, \frac{\partial S}{\partial P}>0, \frac{\partial^{2} S}{\partial P^{2}} \leq 0
$$

$$
\frac{\partial D}{\partial f_{d}}>0, \frac{\partial D}{\partial P} \leq 0 .
$$

These indicate that both supply and demand grow with respect to the time dependent component. That is, over time, all else being equal, we expect that demand will increase for a commodity such as oil, natural gas, and electricity, etc. Likewise, we expect available supply to increase as time goes on, assuming of course that the costs of production do not make additional supply uneconomical. However, the price component of supply is concave with respect to price, indicating 
that producers can produce more product as price increases, but their ability to do so slows. We also assume that demand decreases in price.

Assuming that $f_{i}(t)=\exp \left(a_{i} B(t)_{i}\right)$, where $a_{i}$ is a constant and $B(t)_{i}$ is the stochastic time dependent component, and $g_{i}(P)=P^{b_{i}}$, where $b_{i}$ is also a constant, then a simple example which satisfies the above requirements is:

$$
\ln S=a_{s} B_{s}(t)+b_{s} \ln P,
$$

for the logarithm of supply, and

$$
\ln D=a_{d} B_{d}(t)+b_{d} \ln P,
$$

for the logarithm of demand. This supply function is similar to that used by Ramcharran (2002). However, we include uncertainty into the model through the $B_{i}$ 's, which are scaled by the $a_{i}$ 's, and act like shock parameters. The $b_{i}$ 's are the elasticities of supply and demand. For commodities, demand elasticity is often considered very low (close to 0 ), at least in the short run. In order to satisfy the requirements (1) and (2), we require,

$$
a_{d}, a_{s}>0, b_{d} \leq 0 \text {, and } b_{s} \in(0,1) \text {. }
$$

Given the market clearing condition $D=S$ we obtain,

$$
\ln P=\frac{a_{s} B_{s}(t)-a_{d} B_{d}(t)}{b_{d}-b_{s}},
$$

or

$$
P=\exp \left[\frac{a_{s} B_{s}(t)-a_{d} B_{d}(t)}{b_{d}-b_{s}}\right] .
$$


This indicates that price is a function of the difference between the stochastic components in supply and demand. We also want price to increase in demand. Therefore, we need $-\frac{a_{d}}{b_{d}-b_{s}}>0$ which implies that $b_{d}<b_{s}$.

\subsection{Supply and Demand Dynamics}

The goal of this paper is to provide "simple" models which approximate reality. Consequently we avoid providing complex dynamics for supply, demand, and emission costs. We assume that the stochastic component of demand is an exogenous process described by dynamics:

$$
d B_{d}(t)=\mu_{d} d t+\sigma_{d} d Z_{d}(t)
$$

Here $\mu_{d}$ represents instantaneous demand growth ${ }^{4}$ and $\sigma_{d}$ is the volatility associated with the Brownian motion $Z_{d}$.

Similarly, we model supply with a diffusion process:

$$
d B_{s}(t)=\mu_{s}(t) d t+\sigma_{s} d Z_{s}(t)
$$

Here, $\mu_{s}(t)$ is a time dependent supply growth rate, $\sigma_{s}$ is the volatility parameter and $Z_{s}$ is a Brownian motion. The supply growth rate is written as:

$$
\mu_{s}=\mu_{d}-\gamma c(t)
$$

\footnotetext{
${ }^{4}$ In general, many commodities, particularly electricity and power, are seasonal or multicyclical and it can be important to model these cycles which will cause the growth rate to be time dependent. These time dependent components are unique to commodities and can be dealt with as required. With proper planning the complexity of our model does not become unmanageable.
} 
Here $\gamma$ is a positive constant and $c(t)$ represents the logarithm of emission costs 5 which has mean-reverting dynamics

$$
d c(t)=\kappa(\mu-c(t)) d t+\sigma_{c} d Z_{c}(t)
$$

Here $\kappa$ is the parameter of mean-reversion, $\mu$ is the long run mean of emissions price and $\sigma_{c}$ is a volatility parameter. $Z_{d}, Z_{s}$ and $Z_{c}$ are assumed to be independent Brownian motions. For (6) to make sense, we must consider the units of each of the variables. $\mu_{d}$ represents log units of a good per unit time, and $c(t)$ represents the $\log$ dollar value per log unit of emissions. Thus, $\gamma$ must be the ratio of $\log$ units of emissions to log dollars multiplied by the log unit of log units of a good per unit time. For simplicity it can be thought of as an efficiency parameter. That is, if $\gamma$ is high then the effects of emissions are significant while if $\gamma$ is low then the impact from emissions is low.

Using (3) we can price a number of derivative contracts that include a noisy cost of emissions component.

\subsection{Distribution of Demand and Supply}

Before we price assets it is useful to determine the probability distribution of both demand and supply.

\footnotetext{
${ }^{5} B_{s}$ is likely to be more complex than is proposed, as sudden large shocks can take supply off-line and causing a price jump. A Poisson processes or a Markov chain can be added to the dynamics of supply allowing one to build more realistic processes within the simple framework which we propose. Additionally, assuming that emissions are the only costs which would slow supply growth is perhaps too simple. However, the main goal of this paper it to study emission cost uncertainty.
} 


\subsubsection{Distribution of Demand}

From (4) it is clear that, given the demand $B_{d}(t)$ at time $t$, the stochastic component of demand at time $T$ is normally distributed with mean

$$
\mu_{D e m}(T)=B_{D}(t)+\mu_{d}(T-t),
$$

and variance

$$
\sigma_{D e m}^{2}(T)=\sigma_{d}^{2}(T-t) .
$$

That is $B_{d}(t, T) \sim N\left(\mu_{D e m}(T), \sigma_{D e m}^{2}(T)\right)$.

\subsubsection{Distribution of Emission costs}

The supply distribution function is slightly more complicated than demand, as the supply growth is stochastic and depends on emission costs. Therefore, we first consider the distribution of emission costs. Given $c(t)$ the solution to (7) is either written:

$$
\begin{aligned}
c(T) & =c(t)+\kappa \int_{t}^{T}(\mu-c(u)) d u+\sigma_{c}\left(Z_{c}(T)-Z_{c}(t)\right), \\
\text { or: } \quad & =e^{-\kappa(T-t)}\left(c(t)+\mu\left(e^{\kappa(T-t)}-1\right)+\sigma_{c} \int_{t}^{T} e^{\kappa(u-t)} d Z_{c}(u)\right) .
\end{aligned}
$$

From (10),

$$
-\int_{t}^{T} c(u) d u=\frac{c(T)-c(t)-\kappa \mu(T-t)-\sigma_{c} \int_{t}^{T} d Z_{c}(u)}{\kappa} .
$$

Then from (11) : 


$$
\begin{aligned}
-\int_{t}^{T} c(u) d u & =\frac{e^{-\kappa(T-t)}\left(c(t)+\mu\left(e^{\kappa(T-t)}-1\right)+\sigma_{c} \int_{t}^{T} e^{\kappa(u-t)} d Z_{c}(u)\right)}{\kappa} . \\
& \frac{-c(t)-\kappa \mu(T-t)-\sigma_{c} \int_{t}^{T} d Z_{c}(u)}{\kappa} \\
& =\frac{c(t)}{\kappa}\left(e^{-\kappa(T-t)}-1\right)+\frac{\mu}{\kappa}\left(1-e^{-\kappa(T-t)}-\kappa(T-t)\right) \\
& +\frac{\sigma_{c}}{\kappa} \int_{t}^{T}\left(e^{\kappa(u-T)}-1\right) d Z_{c}(u) .
\end{aligned}
$$

This implies that $-\int_{t}^{T} c(u) d u$ is Gaussian with mean

$$
\begin{aligned}
-\int_{t}^{T} E\left[c(u) \mid \mathcal{F}_{t}\right] d u & =m_{c}(t, T) \\
& =\frac{c(t)}{\kappa}\left(e^{-\kappa(T-t)}-1\right)+\frac{\mu}{\kappa}\left(1-e^{-\kappa(T-t)}-\kappa(T-t)\right) \\
& =\frac{(\mu-c(t))\left(1-e^{-\kappa(T-t)}\right)-\mu \kappa(T-t)}{\kappa}
\end{aligned}
$$

and variance

$$
\begin{aligned}
\sigma_{c}^{2}(t, T) & =\frac{\sigma_{c}^{2}}{\kappa^{2}} E\left[\left(\int_{t}^{T}\left(e^{\kappa(u-T)}-1\right) d Z_{c}(u)\right)^{2}\right] \\
& =\frac{\sigma_{c}^{2}}{\kappa^{2}}\left[\int_{t}^{T}\left(e^{2 \kappa(u-T)}+1-2 e^{\kappa(u-T)}\right) d u\right] \\
& =\frac{\sigma_{c}^{2}}{\kappa^{2}}\left[\frac{\left(1-e^{2 \kappa(t-T)}\right)}{2 \kappa}+(T-t)-\frac{2\left(1-e^{\kappa(t-T)}\right)}{\kappa}\right] .
\end{aligned}
$$

\subsubsection{Distribution of Supply}

The solution of (5) is:

$$
B_{s}(T)=B_{s}(t)+\mu_{d}(T-t)-\gamma \int_{t}^{T} c(u) d u+\sigma_{s} \int_{t}^{T} d Z_{s}(u)
$$


Now since $Z_{s}$ is a Brownian motion, then $B_{s}$ is normally distributed with mean,

$$
\mu_{\text {Sup }}(T)=B_{s}(t)+\mu_{d}(T-t)+\gamma \frac{(\mu-c(t))\left(1-e^{-\kappa(T-t)}\right)-\mu \kappa(T-t)}{\kappa}
$$

and variance

$$
\begin{aligned}
\sigma_{\text {Sup }}^{2}(t) & =V\left[-\gamma \int_{t}^{T} c(u) d \tau+\sigma_{s}\left(Z_{s}(T)-Z_{s}(t)\right]\right. \\
& =\gamma^{2} V\left[\int_{t}^{T} c(u) d u\right]+\sigma_{s}^{2} V\left[Z_{s}(T)-Z_{s}(t)\right] \\
& =\gamma^{2} \frac{\sigma_{c}^{2}}{\kappa^{2}}\left[\frac{\left(1-e^{2 \kappa(t-T)}\right)}{2 \kappa}+(T-t)-\frac{2\left(1-e^{\kappa(t-T)}\right)}{\kappa}\right]+\sigma_{s}^{2}(T-t) .
\end{aligned}
$$

Thus, $B_{s}(t, T) \sim N\left(\mu_{\text {Sup }}(T), \sigma_{\text {Sup }}^{2}(T)\right)$.

\section{Derivatives Pricing}

This section provides the main results of our paper which are formulas for

pricing derivative products using the model in the previous section. A natural question that arises when looking at our model is: why might firms need to consider risks related to the way we have set up our model? (Emissions only affect price through supply growth rates and not instantaneous level changes.) Naturally this framework produces significant effects on prices as time goes by, but little in the way of a clearing price when the time period is small. This may seem unrealistic. However, most emission policies are designed to gradually ease industry into full exposure to emission costs. For example, in Alberta, firms who will face emission costs are benchmarked to a certain number of $\mathrm{CO}_{2}$ equivalent emissions per year during a benchmarking period. Firms which are exposed to emission 
costs are subject to change their behavior relative to the benchmarking period numbers. Similarly, other regulations provide a certain number of free emission credits for the first few years of the program, gradually lowering the number of free credits as time passes so that the effect of emission costs is eventually born by the emitters, (and subsequently the consumer). Though power producers were able to pass along complete or close to complete costs in the EU ETS trading system, we believe that policy makers will try to avoid similar behaviour in the future. Excluding perhaps the the power sector, we believe that our model is a parsimonious model which approximates reality.

\subsection{Profit Flows}

As motivation, we first show that a producer of a product is subject to additional risk in the presence of emission cost uncertainty.

Suppose that a firm is producing $Q$ units of energy which are exposed to emission price uncertainty. The firm is assumed to be operating in a competitive market and is unable to affect price as given in (3). The firm receives profit, $\pi$, for each unit sold to the market and the profit is the difference between revenue $R$ and costs $\hat{\mathcal{C}}$ and can be represented by:

$$
\pi(t)=R(t)-\hat{\mathcal{C}}(t)=Q(P(t)-\mathcal{C}(t))
$$

Here $P$ is the market price as in (3), and $\mathcal{C}$ is the cost of production per unit. Cost is composed of an input price $P_{i n}$, a transformation parameter, $\omega$, which dictates how much of the input is required to produce one unit of output, a cost of emissions, $\varepsilon(t)=e^{c(t)}$, where the dynamics of $c(t)$ are given by (7), and a project specific efficiency parameter, $\gamma_{i d}$, which determines the impact that emission costs have on profits. Costs are thus expressed by: 


$$
\mathcal{C}(t)=P(t)_{i n} \omega+\varepsilon(t) \gamma_{i d}
$$

Profits can then be expressed as:

$$
\pi(t)=Q\left(P(t)-P_{i n}(t) \omega-\varepsilon(t) \gamma_{i d}\right)
$$

Traditionally, producers have not been subject to emission costs and so were exposed to profit uncertainty from only the first two terms in (17). However, in a world where emission costs are included in the profit equation there is now a third source of uncertainty, emission costs. Depending on the values of $\varepsilon(t)$ and $\gamma_{i d}$ this new source of risk could be large.

Even if a single firm does not pay emission costs, so $\gamma_{i d}=0$, it still faces higher profit uncertainty through the output price $P(t)$. By the dynamics of supply (5), it is clear that the inclusion of emission costs in the economy causes output prices to be more uncertain (although with a price that will almost surely be higher as well). Therefore, models that allow firms to hedge their future profit streams in the presence of emission price uncertainty are important. We suggest some solutions to these issues below.

\subsection{Asset Pricing with Emission Uncertainty}

Throughout this paper we shall price assets using a stochastic discount factor, (SDF) $M$. The time $t$ value, $V(t)$ of an asset which has a payoff $X$ which is paid at time $T \geq t \geq 0$ is then given by:

$$
V(t)=E^{\mathcal{P}}\left[\frac{M(T)}{M(t)} X(T) \mid \mathcal{F}(t)\right] .
$$

Here, $\mathcal{P}$ represents the physical or real-world probability, and $\mathcal{F}(t)$ is the information flow up to time $t \geq 0$. For each product, (forwards, options, or physical 
assets), which are to be priced equation (18) will be used. Using this approach, Lyle and Elliott (2009) show that the price of a European call option written on electricity can be found with a price function similar to (3) and a SDF which satisfies $E^{\mathcal{P}}[M X]=e^{-r-\alpha} E^{\mathcal{P}}[X]$ where $r$ is the risk free rate and $\alpha$ represents the market price of risk. We shall also follow this convention within this paper. We first derive an equation for a forward contract. The price of a European call option written on the spot price is then found. Finally, the price of a European call option written on a forward contract is derived.

\subsubsection{Forward Price and Dynamics}

In both energy, and more general commodity markets, forward or futures ${ }^{6}$ contracts play an important, (perhaps vital), role in planning and profitability, as well as in risk management. Indeed, what is often referred to on television as the "price" of a commodity, such as a barrel of oil, is actually the price of a futures contract which is closest to expiration, (also called the prompt month contract), and not the actual cash, or spot, price.

Recall that the price of the asset at time $t \leq T$ in our model is:

$$
P(t)=\exp \left(\frac{a_{s} B_{s}(t)-a_{d} B_{d}(t)}{b_{d}-b_{s}}\right)
$$

Then the price of a forward contract with expiry $T \geq t$ is ${ }^{7}$ :

\footnotetext{
${ }^{6} \mathrm{We}$ assume that forward and future contacts are equal in this paper. However, in reality this is not always the case.

${ }^{7}$ We drop the $\mathcal{P}$ superscript on the above the expectation operator for notational convenience. Unless explicitly stated $E(\cdot)$ represents the expectation taken with respect to the physical measure $\mathcal{P}$.
} 


$$
F(t, T)=E\left[\frac{M(T)}{M(t)} P(T) \mid \mathcal{F}_{t}\right]=e^{-(r+\alpha)(T-t)} E\left[P(T) \mid \mathcal{F}_{t}\right] .
$$

This leads to the first proposition which provides a closed form solution for the forward price:

Proposition 1. Given the pricing equation, (3), and the dynamics of stochastic demand, supply and emissions (4), (5), and (7), the price of a forward contract at time $t$ with expiration $T \geq t \geq 0, F(t, T)$ is:

$$
\begin{aligned}
F(t, T) & =F(0, T) \exp \left(\frac{1}{b_{d}-b_{s}}\left(a_{s} \sigma_{s} Z_{s}(t)-a_{d} \sigma_{d} d Z_{d}(t)\right)\right. \\
& \left.-\frac{1}{2\left(b_{d}-b_{s}\right)^{2}}\left(a_{s}^{2} \sigma_{s}^{2}+a_{d}^{2} \sigma_{d}^{2}\right) t\right)
\end{aligned}
$$

Here

$$
F(0, T)=P(0) G(0, T) J(0, T)
$$

which is the price of the forward contract at time 0 , and

$$
\begin{aligned}
G(0, T) & =\exp \left[\frac{\left(a_{s}-a_{d}\right) \mu_{d}(T)}{b_{d}-b_{s}}+\frac{a_{s} \gamma}{b_{d}-b_{s}} m_{c}(0, T)\right] \\
J(0, T) & =\exp \left(\frac{\sigma_{H}^{2}(0, T)}{2}\right) \\
\sigma_{H}^{2} & =\frac{a_{s}^{2} \gamma^{2}}{\left(b_{d}-b_{s}\right)^{2}} \sigma_{c}^{2}(0, T)^{2}+\frac{a_{s}^{2} \sigma_{s}^{2}}{\left(b_{d}-b_{s}\right)^{2}} T+\frac{a_{d}^{2} \sigma_{d}^{2}}{\left(b_{d}-b_{s}\right)^{2}} T .
\end{aligned}
$$

Proof. From (3) it follows that: 


$$
\begin{aligned}
\frac{P(T)}{P(t)} & =\exp \left(\frac{1}{b_{d}-b_{s}}\left[a_{s}\left(B_{s}(T)-B_{s}(t)\right)-a_{d}\left(B_{d}(T)-B_{d}(t)\right)\right]\right) \\
& =\exp \left(\frac{a_{s}}{b_{d}-b_{s}}\left(\int_{t}^{T} \mu_{s}(u) d u+\sigma_{s} \int_{t}^{T} d Z_{s}(u)\right)-\frac{a_{d}}{b_{d}-b_{s}}\left(\int_{t}^{T} \mu_{d} d u+\sigma_{d} \int_{t}^{T} d Z_{d}(u)\right)\right) \\
& =\exp \left(\frac{\left(a_{s}-a_{d}\right) \mu_{d}(T-t)}{b_{d}-b_{s}}+\frac{a_{s} \gamma}{b_{d}-b_{s}} m_{c}(t, T) \quad\right. \text { from (13) } \\
& +\frac{a_{s} \gamma}{b_{d}-b_{s}} \frac{\sigma_{c}}{\kappa} \int_{t}^{T}\left(e^{\kappa(u-T)}-1\right) d Z_{c}(u) \\
& \left.+\frac{a_{s}}{b_{d}-b_{s}} \sigma_{s} \int_{t}^{T} d Z_{s}(u)-\frac{a_{d}}{b_{d}-b_{s}} \sigma_{d} \int_{t}^{T} d Z_{d}(u)\right) .
\end{aligned}
$$

Write

$$
G(t, T)=\exp \left[\frac{\left(a_{s}-a_{d}\right) \mu_{d}(T-t)}{b_{d}-b_{s}}+\frac{a_{s} \gamma}{b_{d}-b_{s}} m_{c}(t, T)\right]
$$

So

$$
\begin{aligned}
P(T) & =P(t) G(t, T) \exp \left[\frac{a_{s} \gamma}{b_{d}-b_{s}} \frac{\sigma_{c}}{\kappa} \int_{t}^{t}\left(e^{\kappa(u-T)}-1\right) d Z_{c}(u)\right. \\
& \left.\left.+\frac{a_{s}}{b_{d}-b_{s}} \sigma_{s} \int_{t}^{T} d Z_{s}(u)-\frac{a_{d}}{b_{d}-b_{s}} \sigma_{d} \int_{t}^{T} d Z_{d}(u)\right)\right] .
\end{aligned}
$$

Now, since $Z_{c}, Z_{s}, Z_{d}$ are independent Brownian motions,

$$
\begin{gathered}
\frac{a_{s} \gamma}{b_{d}-b_{s}} \frac{\sigma_{c}}{\kappa} \int_{t}^{t}\left(e^{\kappa(u-T)}-1\right) d Z_{c}(u) \\
\left.+\frac{a_{s}}{b_{d}-b_{s}} \sigma_{s} \int_{t}^{T} d Z_{s}(u)-\frac{a_{d}}{b_{d}-b_{s}} \sigma_{d} \int_{t}^{T} d Z_{d}(u)\right)=H\left(Z_{d}, Z_{s}, Z_{c}, T\right)
\end{gathered}
$$

is Gaussian with mean 0 and variance. 


$$
\sigma_{H}(t, T)^{2}=\frac{a_{s}^{2} \gamma^{2}}{\left(b_{d}-b_{s}\right)^{2}} \sigma_{c}^{2}(t, T)^{2}+\frac{a_{s}^{2} \sigma_{s}^{2}}{\left(b_{d}-b_{s}\right)^{2}}(T-t)+\frac{a_{s}^{2} \sigma_{d}^{2}}{\left(b_{d}-b_{s}\right)^{2}}(T-t) .
$$

Therefore,

$$
\begin{aligned}
E\left[P(T) \mid \mathcal{F}_{t}\right] & =P(t) G(t, T) E\left[\exp \left(H\left(Z_{d}, Z_{s}, Z_{c}, T\right)\right) \mid \mathcal{F}_{t}\right] \\
& =P(t) G(t, T) \exp \left(\frac{\sigma_{H}(t, T)^{2}}{2}\right)
\end{aligned}
$$

Thus, the forward price is:

$$
F(t, T)=e^{-(r+\alpha)(T-t)} E\left[P(T) \mid \mathcal{F}_{t}\right]=P(t) \Phi(t, T),
$$

where $\Phi(t, T)=e^{-(r+\alpha)(T-t)} G(t, T) \exp \left(\frac{\sigma_{H}(t, T)^{2}}{2}\right)$.

Now for a fixed $T, F(t, T)$ is a martingale so its differential will only have $d Z$ terms.

That is

$$
\begin{aligned}
d F(t, T) & =\Phi(t, T) \frac{P(t)}{b_{d}-b_{s}}\left(a_{s} \sigma_{s} d Z_{s}(t)-a_{d} \sigma_{d} d Z_{d}(t)\right) \\
& =F(t, T) \frac{1}{b_{d}-b_{s}}\left(a_{s} \sigma_{s} d Z_{s}(t)-a_{d} \sigma_{d} d Z_{d}(t)\right)
\end{aligned}
$$

Thus, the forward price is:

$$
\begin{aligned}
F(t, T)= & F(0, T) \exp \left(\frac{1}{b_{d}-b_{s}}\left(a_{s} \sigma_{s} Z_{s}(t)-a_{d} \sigma_{d} d Z_{d}(t)\right)\right. \\
& \left.-\frac{1}{2\left(b_{d}-b_{s}\right)^{2}}\left(a_{s}^{2} \sigma_{s}^{2}+a_{d}^{2} \sigma_{d}^{2}\right) t\right) .
\end{aligned}
$$




\subsubsection{The Price of a European Call Option on the Spot Price}

Although options written on spot prices may be less common than those written on forward contacts, they are still traded and have important implications for capital budgeting, (for example, when considering the option value of a physical asset). As such, the ability to price these claims is important and the next proposition gives the formula for doing so.

Proposition 2. Given the pricing equation, (3), and the dynamics of stochastic demand, supply and emissions (4), (5), and (7), the price at time t of a European option contract with expiration $T \geq t \geq 0$, and strike price $K$ is:

$$
C(t)=C(t)=e^{-(r+\alpha)(T-t)}\left[e^{\mu_{z}+\frac{\sigma_{z}^{2}}{2}} \Phi\left(d_{1}\right)-K \Phi\left(d_{2}\right)\right]
$$

Here,

$$
\begin{aligned}
d_{1} & =\frac{\sigma_{z}+\mu_{z}-\ln (K)}{\sigma_{z}}, \\
d_{2} & =\frac{\mu_{z}+\log (K)}{\sigma_{z}}=d_{1}-\sigma_{z}, \\
\mu_{z} & =\frac{1}{b_{d}-b_{s}}\left(a_{s} \mu_{\text {sup }}(T)-a_{d} \mu_{\text {dem }}(T)\right), \\
\sigma_{z}^{2} & =\frac{1}{\left(b_{d}-b_{s}\right)^{2}}\left(a_{s}^{2} \sigma_{\text {sup }}^{2}(T)+a_{d}^{2} \sigma_{\text {dem }}^{2}(T)\right) .
\end{aligned}
$$

Proof. Recall that

$$
P(t)=\exp \left(\frac{1}{b_{d}-b_{s}}\left(a_{s} B_{s}(t)-a_{b} B_{d}(t)\right)\right) .
$$

Now since $B_{s}(t)$ and $B_{d}(t)$ are both normally distributed and assumed to be independent,

$\frac{1}{b_{d}-b_{s}}\left(a_{s} B_{s}(t)-a_{b} B_{d}(t)\right)=Z(t) \sim N\left(\frac{1}{b_{d}-b_{s}}\left(a_{s} \mu_{\text {sup }}-a_{d} \mu_{d e m}\right), \frac{1}{\left(b_{d}-b_{s}\right)^{2}}\left(a_{s}^{2} \sigma_{\text {sup }}^{2}+a_{d}^{2} \sigma_{d e m}^{2}\right)\right)$. 
Thus, $P(t)=\exp (Z(t))$.

The price of a call is:

$$
\begin{aligned}
C(t) & =e^{-(r+\alpha)(T-t)} E\left[(P(T)-K)^{+} \mid \mathcal{F}_{t}\right] \\
& =e^{-(r+\alpha)(T-t)} \int_{-\infty}^{\infty}(\exp (Z)-K)^{+} \frac{1}{\sqrt{2 \pi} \sigma_{z}} \exp \left(-\frac{\left(Z-\mu_{z}\right)^{2}}{2 \sigma_{z}^{2}}\right) d Z
\end{aligned}
$$

For the integrand to be non-zero $Z>\ln K$. Therefore,

$$
\begin{aligned}
\int_{-\infty}^{\infty}(\exp (Z)-K)^{+} \frac{1}{\sqrt{2 \pi} \sigma_{z}} \exp \left(-\frac{\left(Z-\mu_{z}\right)^{2}}{2 \sigma_{z}^{2}}\right) & =\int_{\ln K}^{\infty}\left(e^{Z}-K\right) \frac{1}{\sqrt{2 \pi} \sigma_{z}} \exp \left(-\frac{\left(Z-\mu_{z}\right)^{2}}{2 \sigma_{z}^{2}}\right) d Z \\
& =\int_{\ln K}^{\infty} e^{Z} \frac{1}{\sqrt{2 \pi} \sigma_{z}} \exp \left(-\frac{\left(Z-\mu_{z}\right)^{2}}{2 \sigma_{z}^{2}}\right) d Z \\
& -\int_{\ln K}^{\infty} K \frac{1}{\sqrt{2 \pi} \sigma_{z}} \exp \left(-\frac{\left(Z-\mu_{z}\right)^{2}}{2 \sigma_{z}^{2}}\right) d Z \\
& =\int_{\ln K}^{\infty} e^{Z} \frac{1}{\sqrt{2 \pi} \sigma_{z}} \exp \left(-\frac{\left(Z-\mu_{z}\right)^{2}}{2 \sigma_{z}^{2}}\right) d Z \\
& -K \int_{\frac{\ln K-\mu_{z}}{\sigma_{z}} \frac{1}{\sqrt{2 \pi}}}^{\infty} \exp \left(-\frac{(\nu)^{2}}{2}\right) d \nu \\
& =\int_{\ln K}^{\infty} e^{Z} \frac{1}{\sqrt{2 \pi} \sigma_{z}} \exp \left(-\frac{\left(Z-\mu_{z}\right)^{2}}{2 \sigma_{z}^{2}}\right) d Z \\
& -K \Phi\left(\frac{\mu_{z}-\ln (K)}{\sigma_{z}}\right) .
\end{aligned}
$$

Now, 


$$
\begin{aligned}
\int_{\ln K}^{\infty} \exp (Z) \frac{1}{\sqrt{2 \pi} \sigma_{z}} \exp \left(-\frac{\left(Z-\mu_{z}\right)^{2}}{2 \sigma_{z}^{2}}\right) d Z= & \frac{1}{\sqrt{2 \pi} \sigma_{z}} \int_{\ln K}^{\infty} \exp \left(\frac{2 \sigma_{z}^{2} Z-\left(Z^{2}-2 Z \mu_{z}+\mu_{z}^{2}\right)}{2 \sigma_{z}^{2}}\right) d Z \\
= & \frac{1}{\sqrt{2 \pi} \sigma_{z}} \int_{\ln K}^{\infty} \exp \left(-\frac{Z^{2}-2 Z \mu_{z}+\mu_{z}^{2}-2 \sigma_{z}^{2} Z}{2 \sigma_{z}^{2}}\right) d Z \\
= & \frac{1}{\sqrt{2 \pi} \sigma_{z}} \int_{\ln K}^{\infty} \exp \left(-\frac{\left(Z-\left(\sigma_{z}+\mu_{z}\right)\right)^{2}-\left(\frac{\sigma_{z}^{2}}{2}+\mu_{z}\right)}{2 \sigma_{z}^{2}}\right) d Z \\
= & \frac{1}{\sqrt{2 \pi} \sigma_{z}} e^{\left(\frac{\sigma_{z}^{2}}{2}+\mu_{z}\right)} \int_{\ln K}^{\infty} \exp \left(-\frac{\left(Z-\left(\sigma_{z}+\mu_{z}\right)\right)^{2}}{2 \sigma_{z}^{2}}\right) d Z \\
= & \frac{1}{\sqrt{2 \pi}} e^{\left(\frac{\sigma_{z}^{2}}{2}+\mu_{z}\right)} \int_{\frac{\ln K-\left(\sigma_{z}+\mu_{z}\right)}{\sigma_{z}}}^{\infty} \exp \left(-\frac{(Z-\nu)^{2}}{2}\right) d \nu \\
= & e^{\left(\frac{\sigma_{z}^{2}}{2}+\mu_{z}\right)} \Phi\left(\frac{\sigma_{z}+\mu_{z}-\ln (K)}{\sigma_{z}}\right) .
\end{aligned}
$$

So,

$$
C(t)=e^{-(r+\alpha)(T-t)}\left[e^{\frac{\sigma_{z}^{2}}{2}+\mu_{z}} \Phi\left(\frac{\sigma_{z}+\mu_{z}-\ln (K)}{\sigma_{z}}\right)-K \Phi\left(\frac{\mu_{z}-\ln (K)}{\sigma_{z}}\right)\right] .
$$

\subsubsection{The Price of a European Call Option Written on a Forward Contract}

Many option contracts are written on forwards and not on spot prices. Consequently pricing options which are written on forwards is of great importance. The next proposition provides a formula for pricing such options.

Proposition 3. Suppose that a call option is written for which the underlying is a forward contract which the purchaser receives at time $T^{*}$, where the actual forward expires at time $T \geq T^{*} \geq t \geq 0, F\left(T^{*}, T\right)$. Then the price at time $t$ of 
this call, $C\left(T, T^{*}, t\right)$, assuming dynamics described in (4), (5), and (7) and the forward price (20) is:

$$
C\left(T, T^{*}, t\right)=e^{-(r+\alpha)(T-t)}\left[F(t, T) \Phi\left(d_{1}+\sigma_{F}\right)-K \Phi\left(d_{1}\right)\right] .
$$

Here,

$$
\begin{aligned}
d_{1} & =\frac{1}{\sigma_{F}}\left[\log (K / F(t, T))+\frac{\sigma_{F}^{2}}{2}\right], \\
\sigma_{F}^{2} & =\frac{1}{\left(b_{d}-b_{s}\right)^{2}}\left(a_{s}^{2} \sigma_{s}^{2}+a_{d}^{2} \sigma_{d}^{2}\right)\left(T^{*}-t\right) .
\end{aligned}
$$

Proof. We first write $F\left(T^{*}, T\right)$ as a function of $F(t, T)$ :

$$
\begin{aligned}
F\left(T^{*}, T\right) & =F(t, T) \exp \left(\frac{1}{b_{d}-b_{s}}\left(a_{s} \sigma_{s}\left[Z_{s}\left(T^{*}\right)-Z_{s}(t)\right]-a_{d} \sigma_{d}\left[Z_{d}\left(T^{*}\right)-Z_{d}(t)\right]\right)\right. \\
& \left.-\frac{1}{2\left(b_{d}-b_{s}\right)^{2}}\left(a_{s}^{2} \sigma_{s}^{2}+a_{d}^{2} \sigma_{d}^{2}\right)\left(T^{*}-t\right)\right) .
\end{aligned}
$$

Let $\sigma_{F}^{2}=\frac{1}{\left(b_{d}-b_{s}\right)^{2}}\left(a_{s}^{2} \sigma_{s}^{2}+a_{d}^{2} \sigma_{d}^{2}\right)\left(T^{*}-t\right)$, then

$$
F\left(T^{*}, T\right)=F(t, T) \exp \left[-\frac{\sigma_{F}^{2}}{2}+\sigma_{F} \nu\right]=\Psi(\nu),
$$

where, $\nu \sim N(0,1)$.

We need $F\left(T^{*}, T\right) \geq K$, so

$$
\nu \geq \frac{1}{\sigma_{F}}\left[\log (K / F(t, T))+\frac{\sigma_{F}^{2}}{2}\right]=d_{1} .
$$

Let $f(\nu)=\frac{1}{\sqrt{(2 \pi)}} e^{-\frac{\nu^{2}}{2}}$. Then the price of the call written on the forward is: 


$$
\begin{aligned}
C\left(T^{*}, T, t\right)= & e^{-(r+\alpha)\left(T^{*}-t\right)} E\left[\left(F\left(T^{*}, T\right)-K\right)^{+}\right] \\
= & e^{-(r+\alpha)\left(T^{*}-t\right)}\left[\int_{-d_{1}}^{\infty} \Psi(\nu) f(\nu) d \nu\right. \\
& \left.-K \int_{-d_{1}}^{\infty} f(\nu) d \nu\right] \\
= & e^{-(r+\alpha)\left(T^{*}-t\right)}\left[\int_{-d_{1}}^{\infty} \Psi(\nu) f(\nu) d \nu-K N\left(d_{1}\right)\right] .
\end{aligned}
$$

Now,

$$
\begin{aligned}
\int_{-d_{1}}^{\infty} \Psi(\nu) f(\nu) d \nu & =\frac{1}{\sqrt{2 \pi}} \int_{-d_{1}}^{\infty} F(t, T) \exp \left(\frac{-\sigma_{F}^{2}+2 \sigma_{F} \nu-\nu^{2}}{2}\right) d \nu \\
& =\frac{1}{\sqrt{2 \pi}} \int_{-d_{1}}^{\infty} F(t, T) \exp \left(-\frac{\left(\nu-\sigma_{F}\right)^{2}}{2}\right) d \nu
\end{aligned}
$$

Write $y-\nu-\sigma_{F}=-d_{1}-\sigma_{F}$. Then

$$
\begin{aligned}
\frac{1}{\sqrt{2 \pi}} \int_{-d_{1}}^{\infty} F(t, T) \exp \left(-\frac{\left(\nu-\sigma_{F}\right)^{2}}{2}\right) & =\int_{-d_{1}-\sigma_{F}}^{\infty} \exp \left(-\frac{y^{2}}{2}\right) d y \\
& =F(t, T) N\left(d_{1}+\sigma_{F}\right)
\end{aligned}
$$

This gives the desired result:

$$
C\left(T^{*}, T, t\right)=e^{-(r+\alpha)(T-t)}\left[F(t, T) N\left(d_{1}+\sigma_{F}\right)-K N\left(d_{1}\right)\right] .
$$

\section{Estimating the Parameters}

Having provided a number of theoretical results, we now provide insight into how these findings can be implemented and used for actual analysis. We first show 
how the parameters can be estimated and then provide a simulated example using sensible values for our parameters. In each of the above models estimates for $a_{s}, b_{s}, a_{d}, b_{d}, \mu_{d}, \mu_{s}, \sigma_{d}, \sigma_{s}, \gamma, \kappa, \mu, \sigma_{c}$ are required and we show how to find these estimates.

\subsection{Estimating Stochastic Supply and Demand Parameters}

Recall that the following equations describe supply and demand:

$$
\ln S(t)=a_{s} B_{s}(t)+b_{s} \ln P(t),
$$

for the logarithm of supply, and

$$
\ln D(t)=a_{d} B_{d}(t)+b_{d} \ln P(t)
$$

for the logarithm of demand.

In all cases we believe a reasonable proxy of time dependent demand growth should approximate economic growth. For power, economic growth will be highly region specific. However, for assets such as oil or coal, global growth parameters should likely be used. The pricing equation hinges on the ability to identify $B_{s}(t)$ and $B_{d}(t)$ which is not always obvious. For electricity, this much easier to do than for other industries. Take for instance, the production of oil. One can assume that the process describing stochastic demand can be proxied reasonably well by global consumption. For stochastic supply this is not so obvious. However, one might use traditional production as a proxy for oil, that is, those types of reserves that have been used in the past for producing oil, such as the fields in Saudi Arabia. In the absence of additional costs, new sources of oil, such as oil or tar sands, 
may come on-line to add to and fill the void left by declining traditional reserves. However, in the presence of emission costs the growth rate of $B_{s}(t)$ will slow.

To find the parameters for the stochastic process defining $B_{s}(t)$ and $B_{d}(t)$ standard approaches for estimating diffusion processes can be used. These include estimating $\mu_{d}$ from the mean of historical demand, (or consumption), and $\sigma_{d}^{2}$ from historical demand variance. That is

$$
\begin{aligned}
\mu_{d} & =E\left[d \ln X_{\text {consuption }}(t)\right] \\
\text { and } \sigma_{d}^{2} & =V\left[d \ln X_{\text {consuption }}(t)\right] .
\end{aligned}
$$

Estimating supply is slightly more complicated as one must consider emission costs and dynamics. However, we propose the following approach. Since emission costs are either not yet relevant in a given market or have only been trading for only a few years we suggest using historical data which was not exposed to emission trading costs, that is, when $\varepsilon=0$ :

$$
\sigma_{s}^{2}=V\left[d B_{s}(t)\right]
$$

Here $B_{s}$ can be proxied using various measures of production changes, such as base-load power for the electricity industry.

\subsection{Estimating $\gamma$}

Finding the long run value of emissions is difficult and may be highly dependent on government regulation and regional nuances. Therefore, we propose the following simple method of deriving a long term price.

Suppose that an electricity market consists of nuclear, coal and natural gas generation. Nuclear bids into the market for free, coal has a higher marginal cost, but is still a price taker, so they bid in above nuclear power, and natural gas has 
the highest marginal cost and sets the price in the market. In the the absence of an emission cost the bidding behavior looks like :

\begin{tabular}{|c|c|}
\hline Fuel & Bid/MWh \\
\hline Nuclear & 0 \\
\hline Coal & $P_{1}$ \\
\hline Natural Gas & $P_{2}$ \\
\hline
\end{tabular}

Here $P_{2}>P_{1}>0$ sets the price in the market, (on average). Now suppose that an emission cost, $\varepsilon$, is placed into the market then the bidding schedule now becomes:

\begin{tabular}{|c|c|}
\hline Fuel & Bid/MWh \\
\hline Nuclear & 0 \\
\hline Coal & $P_{1}+\varepsilon$ \\
\hline Natural Gas & $P_{2}+\rho \varepsilon$ \\
\hline
\end{tabular}

Emissions do not effect nuclear generation because it does not produce emissions, (at least not $\mathrm{CO}_{2}$ or equivalents). However, it does come into play for coal and natural gas generation. So long as $P_{1}+\varepsilon$ is lower than $P_{2}+\rho \varepsilon$, natural gas is still the highest cost producer. The market price will be $P_{2}+\rho \varepsilon$, where $\rho$ is a parameter that measures the number of emission equivalents per unit produced by natural gas. (Coal is assumed to produce one emission equivalent per MWh and nuclear none). In theory, one might expect $\varepsilon=\frac{P_{2}-P_{1}}{1-\rho}$, which would place the emission cost at the point where producers become indifferent between supplying the market with coal or natural gas, (the switching price).

Recall that the stochastic component of supply is represented by:

$$
d B_{s}(t)=\left(\mu_{d}-\gamma c(t)\right) d t+\sigma_{s} d Z_{s}(t) .
$$


Thus, $\gamma$ represents an efficiency factor that limits growth of traditional, (or dirty), supply, for instance, traditional coal generation. In an emission reducing world, we would like to cease, (or shrink), growth in the traditional supply of production. This does not suggest that no new coal generation or equivalents in other industries may come on-line, only that it will probably be coal generation with a more efficient or clean technology than traditional supply and so will probably be more expensive. Then $\gamma$ is chosen such that in equilibrium,

$$
\mu_{d}-\gamma c(t)=0 .
$$

Recall fin the previous sections that $c=\ln \varepsilon$, so we find that,

$$
\gamma=\frac{\mu_{d}}{\ln \varepsilon} .
$$

This transforms the supply dynamics into:

$$
d B_{s}(t)=\left(\mu_{d}\left(1-\frac{1}{\ln \varepsilon}\right) c(t)\right) d t+\sigma_{s} d Z_{s}(t) .
$$

In theory the long run mean, $\mu$, should approach the switching price which can be estimated using the marginal costs associated with producing power from coal and gas. Additionally the implied switching rate can be recovered from actual emission prices.

In general $\varepsilon$ will be dynamic and can also be modeled using a stochastic differential equation. However, we leave this more realistic and complex approach for further research. Additionally, there may be policy and other regulation shifts which would cause $\varepsilon$ to jump up or down. Further work which models these shifts, (using Markov chains for instance), would be of interest. 


\subsection{Calibration the Emissions Process}

The calibration of an emissions process can be very difficult because there are few markets which currently have traded emission contracts. We propose to use the market data from the European Trading system to approximate the dynamics within a market. We model the log price of emission as a mean-reverting process, which when discretized is simply an $\mathrm{AR}(1)$ process. Then one can use the following dynamics to estimate $\mu, \kappa$ and $\sigma_{c}$ :

$$
\begin{gathered}
c(t+\delta t)=a+b c(t)+\hat{\sigma} \epsilon(t), \\
a=\mu\left(1-e^{-\kappa \delta t}\right), \\
b=e^{-\kappa \delta t} \\
\hat{\sigma}^{2}=\sigma_{c}^{2} \frac{\left(1-e^{-2 \kappa \delta t}\right)}{2 \kappa}
\end{gathered}
$$

Standard linear regression or maximum likelihood methods can be used to estimate the values. The estimate obtained for $\mu$ can be considered the market implied log switching price.

\subsection{Estimating Supply and Demand Elasticities of Price}

Price elasticity, $b$, is defined to be the percentage change in quantity, $Q$, of a good supplied divided by the percentage change in price:

$$
b=\frac{\partial \ln Q}{\partial \ln P} .
$$

It is usually difficult to estimate price elasticities. However, there are some methods to estimate these numbers, for instance, error correction models, bottomup models, and log-linear models. See, for example Hamilton (2009), Lijesen (2007) and references therein. 
Historical elasticity estimates suggest that demand elasticity, $b_{d}$, is quite low. Krichene (2002) finds that demand elasticities are around -0.02 for oil ${ }^{8}$ and -0.01 to 0.04 for natural gas during 1973-1999, while supply elasticities $\left(b_{s}\right)$ are -0.07 to 0.01 for oil and -0.01 to 0.06 for natural gas during the same period. Lijesen (2007) estimates demand elasticities for electricity also to be quite low and indicates that the numbers range from -0.85 to -0.09 for the short run and -0.88 to -0.04 for the long run. Little work has been done trying to estimate supply elasticities for electricity, but one would also expect them to be quite low. (That is, it takes a large price move to induce a small amount of additional supply). Additionally, one can observe, (in some markets), the bid stack within the electricity market and estimate the elasticity directly.

Generally, elasticity tends to be lower in the short run and higher in the long run. Given the discrepancies in long and short run elasticities, depending on the length of the prospective investments, mixtures of these numbers may be required.

\subsection{Estimating $a_{s}$ and $a_{d}$}

In both of the equations, supply and demand possibly have upward drift components which may yield unreliable estimates. Let $X_{d}(t)=\ln D(t)$ and $X_{p}(t)=$ $\ln P(t)$ and $X_{s}(t)=\ln S(t)$. Then

$$
X_{s}(t)=a_{s} B_{s}(t)+b_{s} X_{p}(t)
$$

\footnotetext{
${ }^{8}$ Cooper (2003) also estimates the price elasticity of crude oil demand for 23 countries. For 21 of the 23 countries, the estimates are between -0.109 to -0.016 for short run with exception of China (0.001) and Portugal (0.023). They are between -0.568 and -0.033 for long term, with exception of China (0.005) and Portugal (0.038).
} 
and

$$
X_{d}(t)=a_{d} B_{d}(t)+b_{d} X_{p}(t)
$$

This implies that:

$$
X_{P}(t)=\frac{a_{s}}{b_{d}-b_{s}} B_{d}(t)-\frac{a_{d}}{b_{d}-b_{s}} B_{s}(t) .
$$

Thus the dynamics for log price are:

$$
d X_{P}(t)=\frac{a_{s}}{b_{d}-b_{s}} d B_{d}(t)-\frac{a_{d}}{b_{d}-b_{s}} d B_{s}(t) .
$$

Writing each equation in discrete time:

$X_{p}(t)-X_{p}(t-\delta t)=\frac{a_{s}}{b_{d}-b_{s}}\left(B_{s}(t)-B_{s}(t-\delta t)\right)-\frac{a_{d}}{b_{d}-b_{s}}\left(B_{d}(t)-B_{d}(t-\delta t)\right)$.

As the elasticities are assumed to be known, (suggested ranges are presented in the previous subsection), one can use the proxies which were chosen for both $B_{d}(t)$ and $B_{s}(t)$ and then estimate $a_{s}$ and $a_{d}$.

\section{Simulations}

To provide an example of estimation we show one can generate price paths using Monte Carlo simulation. To obtain approximate values for emissions we use daily closing futures prices (December 2009 expiration) for EU ETS contracts from January 12007 to June 62009 . The initial value for carbon is set at $\$ 18$ and the long term value is set to $\$ 24$. For an estimate of the supply and demand elasticities we use values which are within those presented in section 4.4 , and 
Table 1: Model Parameters for Simulation

\begin{tabular}{|c|c|c|c|}
\hline Parameter & Value & Parameter & Value \\
\hline \hline$b_{s}$ & 0.06 & $b_{d}$ & -0.04 \\
\hline$a_{s}$ & 0.085 & $a_{d}$ & 0.12 \\
\hline \multicolumn{5}{|c|}{} \\
\hline$\mu_{s}$ & $\mu_{d}-\gamma c(t)$ & $\mu_{d}$ & 0.02 \\
\hline$\sigma_{s}$ & 0.45 & $\sigma_{d}$ & 0.15 \\
\hline \multicolumn{5}{|c|}{} & \\
\hline$\gamma$ & 0.064 & $\mu$ & 3.18 \\
\hline$\kappa$ & 1.00 & $\sigma_{c}$ & 0.50 \\
\hline$c(0)$ & 2.89 & & \\
\hline \multicolumn{5}{|c|}{} & & \\
\hline$B_{s}(0)$ & 9.5 & $B_{d}(0)$ & 10 \\
\hline$P(0)$ & 50 & & \\
\hline
\end{tabular}

choose $b_{s}=0.06$ and $b_{d}=-0.04$. For demand growth we use a $2 \%$ annual growth rate, and a $15 \%$ annual volatility. We choose the supply volatility parameter to be $45 \%$ annually. In choosing $a_{s}$ and $a_{d}$ we first set $a_{d}=0.12$, and then select $a_{s}$ so that the initial price is $P(0)=\$ 50, B_{s}(0)=9.5$ and $B_{d}(0)=10$. These values are summarized in Table 1.

\subsection{Profit Flows}

Using the values in Table 1 we simulated 1000 sample paths with 2500 trading days, (250 trading days are assumed to equal one year), for emission prices, demand, supply without emission costs, supply with emission costs, and prices with and without emission costs. Figure 1 shows average price paths with and without 
emissions. From the figure it is clear that emission costs play a significant role in longer term pricing. However, they have little impact, (on the output price), in the early trading period which is what we would expect.

Figure 1: Average simulated path based on 1000 simulations
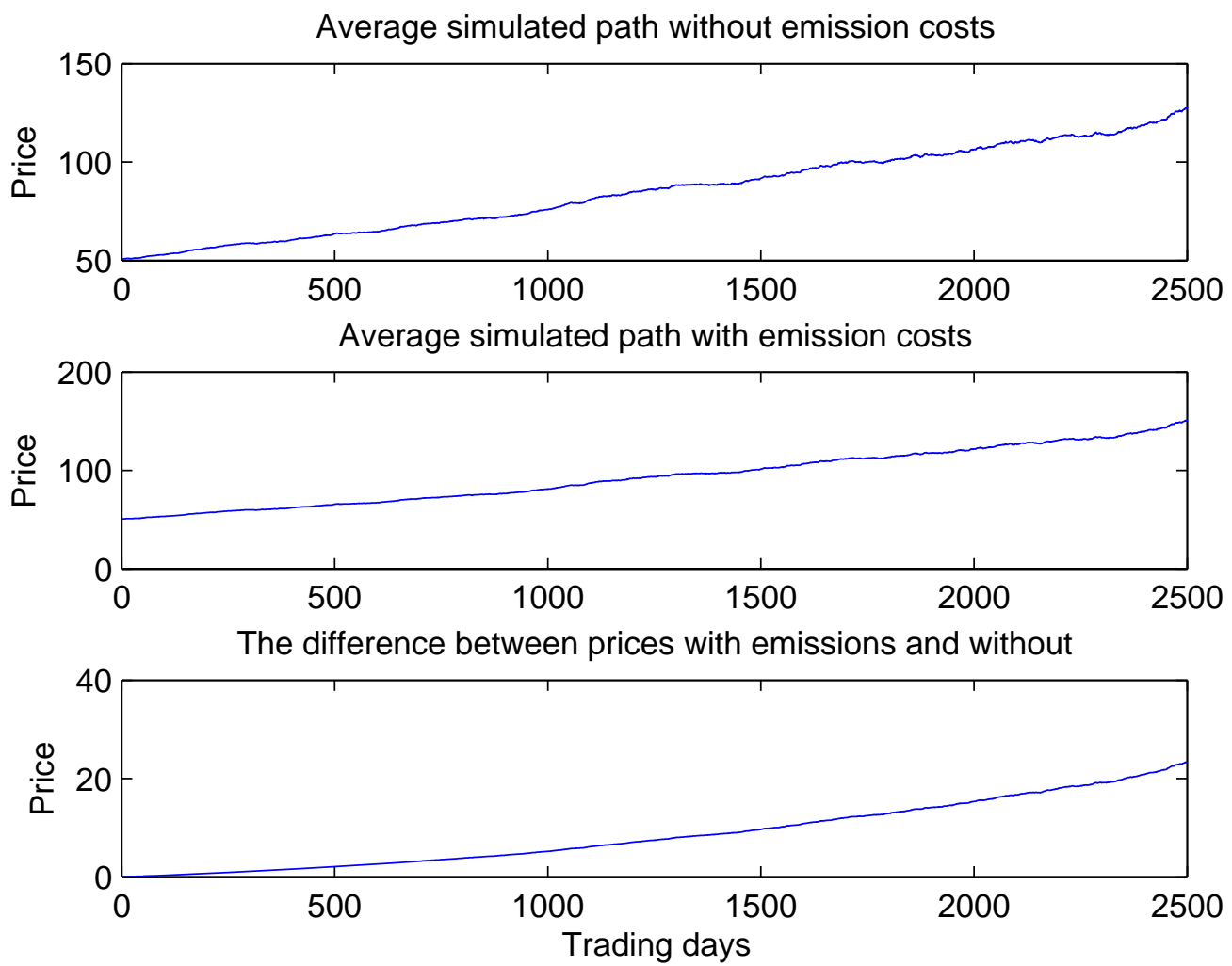

To understand how emissions might affect an individual project, we simulate cash flows using (17). We generate paths for the input cost using a geometric Brownian motion with an initial value of $\$ 80$, an annual growth rate of 0.02 and annual volatility of $30 \%$. We also set $\omega=0.5$. The project is exposed to an emission cost for each unit output. Figure 2 shows average profits less the profits in a non-emission environment, with the individual efficiency parameter set to 
$\gamma_{i d}=[0.25,0.5,0.75,1]$. That is, we simulate profit paths where output price is free from emission costs, as in the top plot in Figure 1, and we simultaneously simulate profit paths where emission costs are present, as in the middle plot in Figure 1. The difference is found between profits generated in an emission costs environment and profits in an non-emissions world. In each case profits start lower when emission costs are present, but as time progresses, profits in the emission costs world begin to overtake the non-emission world. (This is caused by the same phenomenon seen in Figure 1). What is striking is the lower plot in Figure 2, which represents cumulative profits, and shows that several of the projects in an emission costs world have sustained lower, (even negative), profits than in a world without emission costs. This undoubtedly has significant consequences when evaluating physical asset values. One must recognize that it may take some time before the output price reaches a level where a high emission cost project will attain a positive net present value, (NPV), relative to a non-emission cost world. Figure 3 shows a simulated profit path for a project facing emission costs compared with one without. As observed, the profit paths are noticeably different from one another. This reinforces our suggestion that risk management approaches should be modified in a stochastic emission cost regime.

In the next section we how asset values are affected by the inclusion of emission costs.

\subsection{The Value Effects of Emissions on Generation Assets}

The value of a physical asset is the discounted expected payoff of the future profits from the asset. That is 
Figure 2: Profit differences between a world where emission costs are present and where they are not.
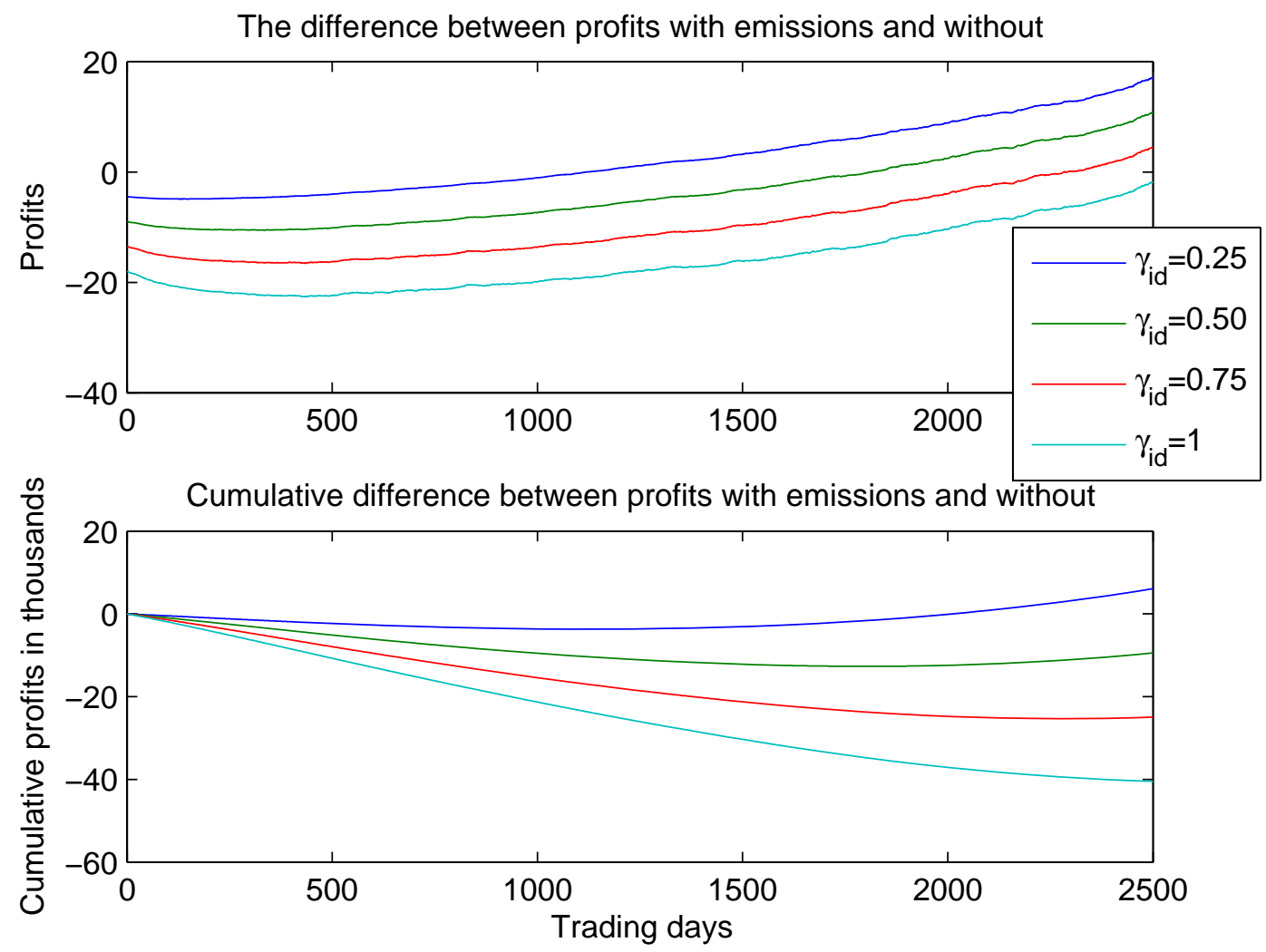

$$
\begin{aligned}
V_{p h y}(t) & =E\left[\int_{t}^{T} \frac{M(\tau)}{M(t)} \pi(\tau) d \tau\right] \\
& =e^{-\left(r_{c}\right)(T-t)} E\left[\int_{t}^{T} \pi(\tau) d \tau\right] .
\end{aligned}
$$

Here, $r_{c}$ represents the required cost of capital, or the hurdle rate, which a firm requires, and $\pi$, as above, represents profits as described in (17). To consider future profits we should use a discrete time model and consider the following expression, assuming that quantity, $Q$, is fixed: 
Figure 3: A simulated profit flow path showing the difference in risk when operating in a world of emission costs compared with one without.

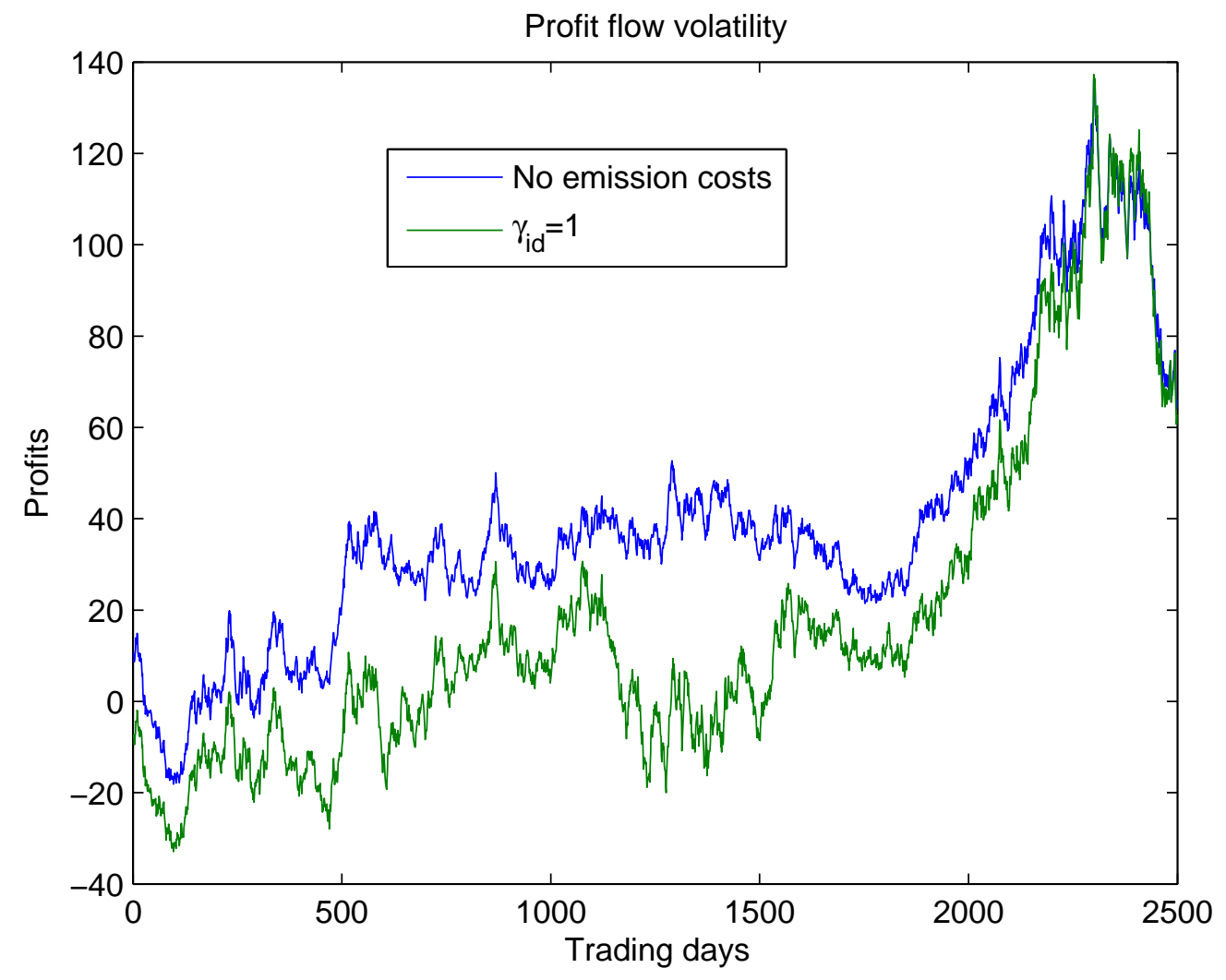

$$
\begin{aligned}
E\left[\sum_{i=1}^{T} \pi(t+i)\right] & =E\left[Q(P(t)-\mathcal{C}(t))+Q \sum_{i=1}^{T} F(t, t+i)-\mathcal{C}(t+i)\right] \\
& =Q E\left[P(t)-\mathcal{C}(t)+\sum_{i=1}^{T} F(t, t+i)-\mathcal{C}(t+i)\right]
\end{aligned}
$$

Here we use the forward price for dates beyond $t$, as they represent what the market is willing to pay for that good at some future date. Suppose, for instance, we wish to evaluate the project on a per quantity basis. Then we set $Q=1$.

So from (26) and (20), expected future profits are: 


$$
\begin{aligned}
E\left[\sum_{i=1}^{T} \pi(t+i)\right]= & E\left[(P(t)-\mathcal{C}(t))+\sum_{i=1}^{T} F(t, t+i)-\mathcal{C}(t+i)\right] \\
= & E\left[(P(t)-\mathcal{C}(t))+\sum_{i=1}^{T} P(t) e^{-(r+\alpha)(i)} G(t, t+i) \exp \left(\frac{\sigma_{H}(t, t+i)^{2}}{2}\right)-\mathcal{C}(t+i)\right] \\
= & P(t)\left[1+\sum_{i=1}^{T} e^{-(r+\alpha)(i)} G(t, t+i) \exp \left(\frac{\sigma_{H}(t, t+i)^{2}}{2}\right)\right] \\
& -E\left[\mathcal{C}(t)+\sum_{i=1}^{T} \mathcal{C}(t+i)\right] .
\end{aligned}
$$

Thus, it follows that expected future revenues are:

$$
\begin{aligned}
E\left[\sum_{i=1}^{T} R(t)\right] & =E\left[\sum_{i=1}^{T} \pi(t+i)\right]+E\left[\mathcal{C}(t)+\sum_{i=1}^{T} \mathcal{C}(t+i)\right] \\
& =P(t)\left[1+\sum_{i=1}^{T} e^{-(r+\alpha)(i)} G(t, t+i) \exp \left(\frac{\sigma_{H}(t, t+i)^{2}}{2}\right)\right]
\end{aligned}
$$

As in (17), costs are composed of an input price $P_{i n}$ and an emission cost which implies that,

$$
\begin{aligned}
E\left[\mathcal{C}(t)+\sum_{i=1}^{T} \mathcal{C}(t+i)\right] & =\mathcal{C}(t)+E\left[\sum_{i=1}^{T} F_{i n}(t, t+i) \omega+e^{c(t+i)} \gamma_{i d}\right] \\
& =\mathcal{C}(t)+\gamma_{i d} \sum_{i=1}^{T} e^{\mu_{c}(t+i)+\frac{\sigma_{\varepsilon}^{2}(t+i)}{2}}+\omega \sum_{i=1}^{T} E\left[F_{i n}(t, t+i)\right] .
\end{aligned}
$$

Here, $\mu_{c}(t)=\mu\left(1-e^{-\kappa t}\right), \sigma_{\varepsilon}^{2}(t)=\frac{\sigma_{c}^{2}}{2 \kappa}\left(1-e^{-2 \kappa t}\right)$, and $F_{i n}(t, t+i)$ represents the price of a forward contract for the input good. 


\subsubsection{Numerical Example}

Suppose that we wish to value a plant which transforms an input, (say coal, oil, natural gas or some other commodity), into an output. Then the plant receives revenue from the sale of the output and generates costs from the purchase and transformation of the input into the output. For simplicity we assume that the input cost follows a geometric Brownian motion:

$$
d P_{\text {in }}(t)=\mu_{\text {in }} P_{\text {in }}(t) d t+\sigma_{\text {in }} P_{\text {in }}(t) d Z_{\text {in }}(t) .
$$

This is log normally distributed with mean

$$
E\left[\ln P_{i n}(T)\right]=\mu_{i n}(T)=\mu_{i n}(T-t),
$$

and variance

$$
V\left[\ln P_{i n}(T)\right]=\sigma_{i n}^{2}(T)=\sigma_{i n}^{2}(T-t) .
$$

Thus the forward price for the input cost is:

$$
F(t, T)=e^{-\left(r+\alpha_{i n}\right)(T-t)} E\left[P_{i n}(T)\right]=P_{i n}(t) e^{-\left(r+\alpha_{i n}-\mu_{i n}\right)(T-t)} .
$$

Here $\alpha_{i n}$ is the market price of risk for the input cost. We assume that forwards are not readily available for emission costs.

Expected profits are thus:

$$
\begin{aligned}
E\left[\sum_{i=1}^{T} \pi(t+i)\right]= & P(t)\left[1+\sum_{i=1}^{T} e^{-(r+\alpha)(i)} G(t, t+i) \exp \left(\frac{\sigma_{H}(t, t+i)^{2}}{2}\right)\right] \\
& -P_{i n}(t) \omega\left[1+\sum_{i=1}^{T} e^{-\left(r+\alpha_{i n}-\mu_{i n}\right)(T-t)}\right] \\
& -\gamma_{i d}\left[e^{c(t)}+\sum_{i=1}^{T} e^{m_{c}(t+i)+\frac{\sigma_{c}^{2}(t+i)}{2}}\right] .
\end{aligned}
$$




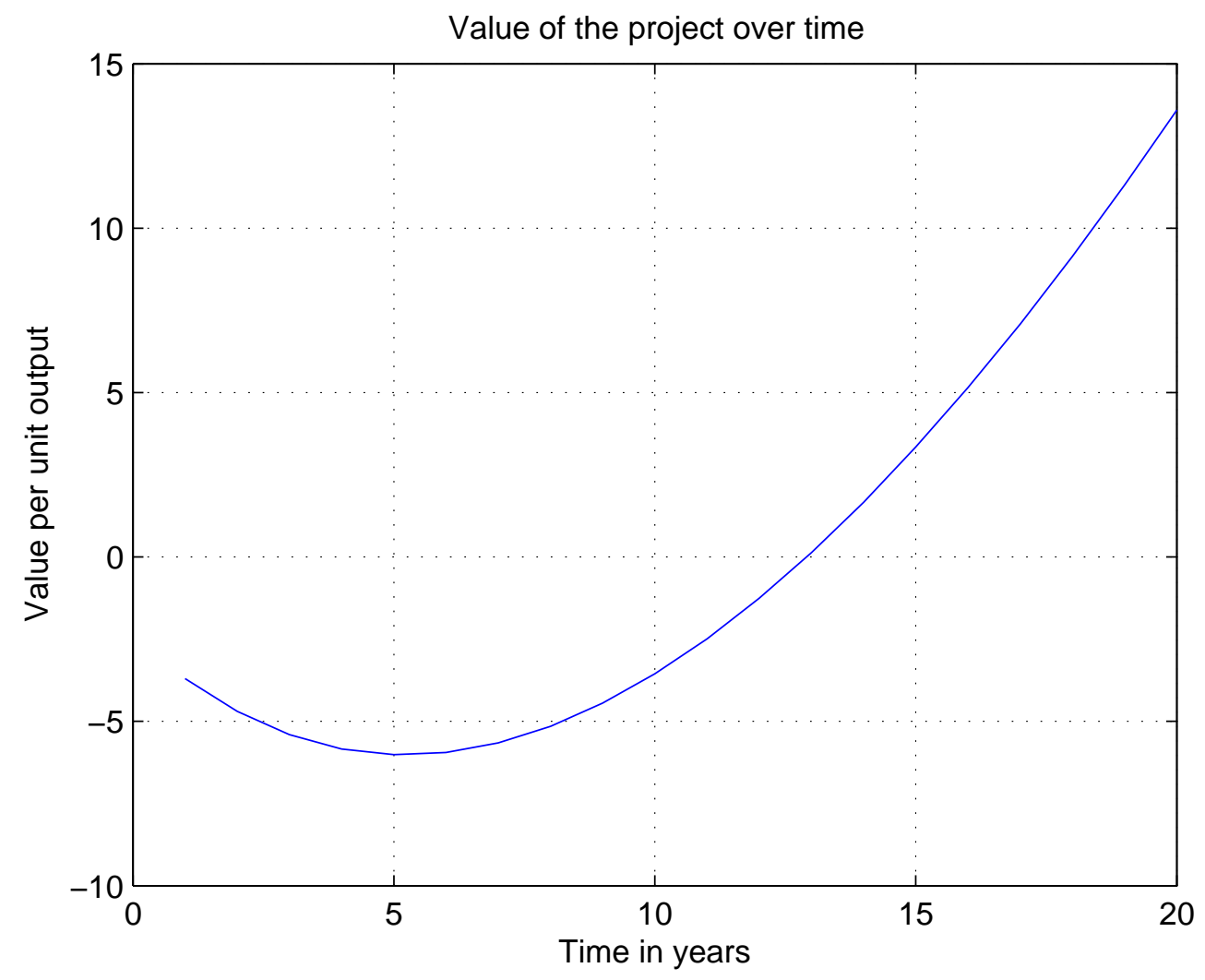

Figure 4: The value of a project exposed to emission costs.

Using this model with the values in Table 1 and setting $\alpha=\alpha_{i n}=0.05$, $\mu_{\text {in }}=0.02, \omega=0.5, \gamma_{i d}=1, r_{c}=0.15$ and $P_{\text {in }}(t)=80$. Figure 4 shows the valuation at various times. The project is not NPV positive unless the time horizon is aproximately less than 13 years.

Figure 5, gives the value of the project with a time horizon of 20 years when $\varepsilon$ varies from $\$ 24$ to $\$ 123$. This corresponds to about a $16 \%$ difference in valuation. Given that this project is valued on a per unit basis, a project worth billions (which can certainly be the case for energy projects) could be mis-valued by hundreds of 


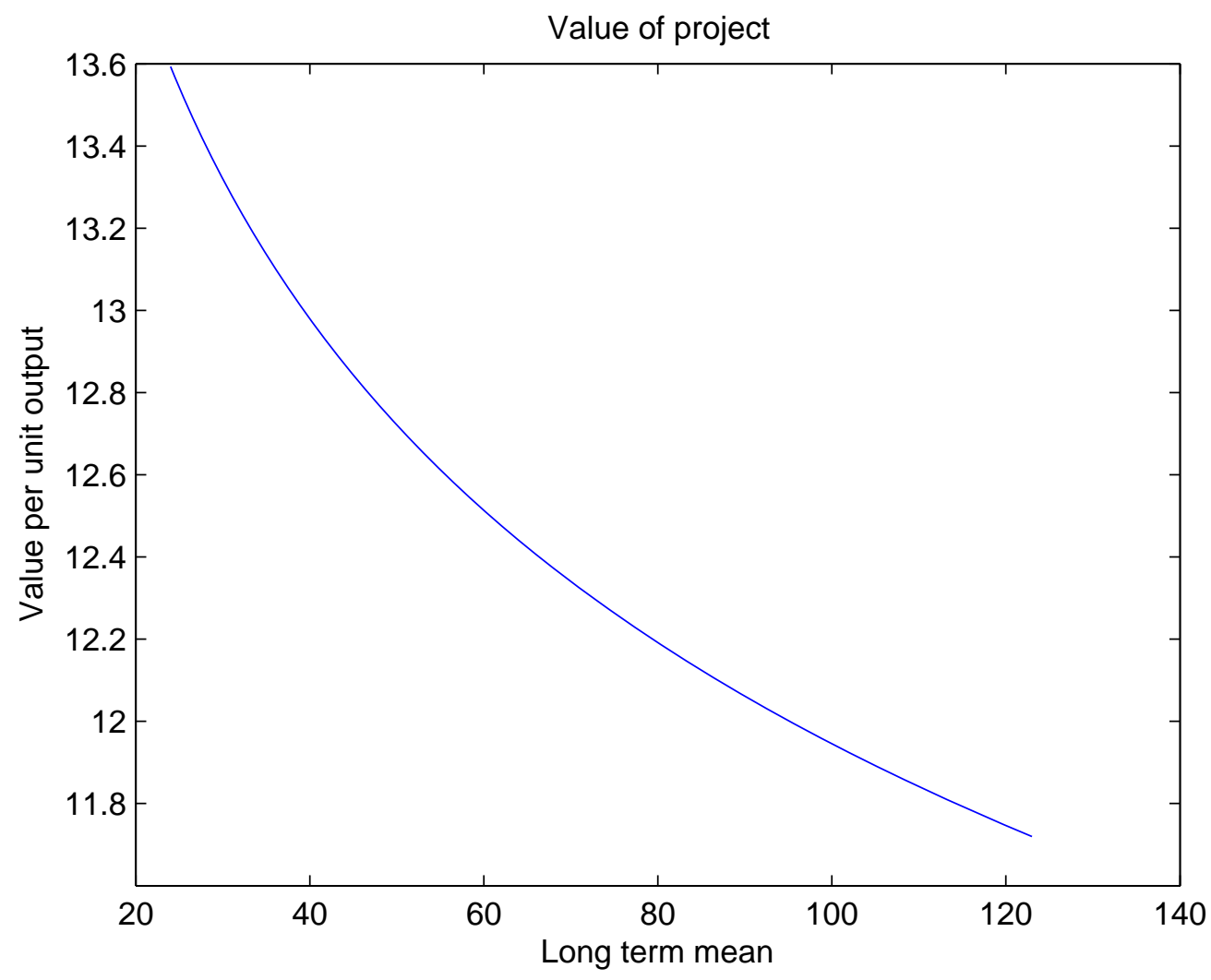

Figure 5: The value of a project with a 20 year horizon and the long term mean cost of emissions varying from $\$ 24$ to $\$ 123$.

millions if $\varepsilon$ is significantly mis-estimated.

\section{Conclusion}

In this paper we introduced a supply-demand framework in which an equilibrium price was found in the presence of emission costs. The results are of interest because firstly, the impact of emissions is included into the equilibrium price over time, and is not passed on instantaneously. This appears to contradict some empirical evidence observed for electricity prices in Europe. However, our model is 
general and attempts to be applicable to the energy sector in general, additionally we believe that new government policies will be such that the price of these goods does not jump (or by not as much) immediately upon initiation of an emission costs environment. Secondly, the stochastic nature of emission costs have little impact on price fluctuation on output prices, but instead induce a significant risk to individual projects which face large emission costs. This is the main and most interesting result of the paper which pertains to real asset valuation. That is, at the project level, costs jump instantaneously but output prices do not. A consequence is that many traditional projects, which otherwise would have been NPV positive, may now be non-economical unless long term horizons are considered. Similarly, profit flow risk is higher in a stochastic emissions environment.

We believe that this paper presents a model which is intuitive and provides interesting insights into how assets might be valued in a emission environment when producers cannot pass along the cost of emissions instantaneously. However, the paper should be regarded as an initial effort in this type of modeling and, therefore, there are many future research areas which will be of interest. In particular, more realistic processes for supply and demand, such as mean reversion or regime switching models, would be applicable. Also, a model which allows for instantaneous jumps in price levels because of emission costs would be a natural extension. A simple such model could be developed using a framework similar to ours except one might replace $\ln (P)$ with $\ln (P-q \varepsilon)$ in both of the supply and demand equations. Here $\varepsilon$ is a stochastic process representing emission costs and $q$ is a scalar multiplier which indicates to what degree emission costs are passed through to the consumer. This would produce results which might be more in line with what has been observed in Europe. The pricing of derivatives and other 
assets would be a simple extension of the work done here.

\section{References}

Anderson, C., 2004. A hybrid model for electricity spot prices. Ph.D. thesis, University of Western Ontario, London, ON, Canada.

Anderson, C., Davison, M., 2008. A hybrid system-econometric model for electricity spot prices: Considering spike sensitivity to forced outage distributions. IEEE Transactions on Power Systems 23 (3), 927-937.

Benz, E., Trück, S., 2009. Modeling the price dynamics of $\mathrm{CO}_{2}$ emission allowances. Energy Economics 31, 4-15.

Bessembinder, H., Lemmon, M., 2002. Equilibrium pricing and optimal hedging in electricity forward markets. Journal of Finance 57, 1347-1382.

Bunn, D., Fezzi, C., 2007. Interaction of european carbon trading and energy prices, fondazione Eni Enrico Maattei Working Paper, No. 123.

Cartea, A., Villaplana, P., 2008. Spot price modeling and the valuation of electricity forward contracts: The role of demand and capacity. Journal of Banking and Finance 32 (12), 2502-2519.

Cooper, J., 2003. Price elasticity of demand for crude oil: Estimates for 23 countries. OPEC Review, 1-8.

Daskalakis, G., Markellos, R., 2009. Are electricity risk premia affected by emission allowance prices? Evidence from EEX, nord pool and powernext. Energy Policy, Forthcoming. 
Davison, M., Anderson, L., Marcus, B., Anderson, K., 2002. Development of a hybrid model for electricity spot prices. IEEE Transactions on Power Systems $17(2), 257-264$.

Deng, S., Oren, S., 2006. Electricity derivatives and risk management. Energy 31, 940-953.

Eyderland, A., Wolyniec, K., 2003. Energy and Power Risk Management. Wiley \& Son.

Frauendorfer, K., Güssow, J., 2009. Clean valuation with regard to EU emission trading. In: Kallrath, J., Pardalos, P., Rebennack, S., Scheidt, M. (Eds.), Optimization in Energy Industry. Springer Berlin Heidelberg, Ch. 20, pp. 461-483.

Hamilton, J., 2009. Understanding crude oil prices. Energy Journal 30 (2), 179_ 206.

Kara, M., Syri, S., Lehtilä, A., Helynen, S., Kekkonen, V., 2008. The impact of EU $\mathrm{CO}_{2}$ emissions trading on electricity markets and electricity consumers in finland. Energy Economics 30, 193-211.

Krichene, N., 2002. World crude oil and natural gas: A demand and supply model. Energy Economics 24, 557-576.

Lijesen, M., 2007. The real-time price elasticity of electricity. Energy Economics 29, 249-258.

Longstaff, F., Wang, A., 2004. Electricity forward prices: A high-frequency empirical analysis. Journal of Finance 59 (4), 1877-1900. 
Lucia, E., Schwartz, J., 2002. Electricity prices and power derivatives: Evidence from the nordic power exchange. Review of Derivatives Research 5, 5-50.

Lyle, M., Elliott, R., 2009. A 'simple' hybrid model for power derivatives. Energy Economics, Forthcoming.

Paolella, M., Taschini, L., 2008. An econometric analysis of emission allowance prices. Journal of Banking and Finance 32, 2022-2032.

Pirrong, C., Jermakyan, M., 2008. The price of power: The valuation of power and weather derivatives. Journal of Banking and Finance 32, 2520-2529.

Ramcharran, H., 2002. Oil production responses to price changes: an empirical application of the competitive model to opec and non-opec countries. Energy Economics 24 (2), 97 - 106.

Seifert, J., Ührig-Homburg, M., W. M., 2008. Dynamic behavior of $\mathrm{CO}_{2}$ spot prices. Journal of Environmental Economics and Management 56, 180-194.

Veith, S., Werner, J., Zimmermann, J., 2009. Capital market response to emission rights returns: Evidence from the european power sector. Energy Economics 31, 605-613.

Vucetic, S., Tomsovic, K., Obradovic, Z., 2001. Discovering price-load relationships in california's electricity market. IEEE Transactions on Power Systems 16 (1), 280-286. 